\title{
Stratagem of Chinese political discourse
}

\author{
Evgenia Fedorovna Serebrennikova ${ }^{1^{*}}$, Victoria Pavlovna Balashova ${ }^{1}$, Mikhail Leonidovich Rybalko ${ }^{1}$ \\ ${ }^{1}$ Institute of Philology, Foreign Languages and Media Communication, Irkutsk State University, 664025, Irkutsk, Lenin str., 8, \\ Russia
}

\begin{abstract}
The article is dedicated to the study of the stratagem of the Chinese media discourse as a special way of structuring a discursive position that contributes to its dominance in communication. Because of the analysis of the corpus of media texts of the Chinese political discourse, it is established that stratagem manifests itself in the coordinates of the political macro-communication, which has an agonal character, and is focused on achieving a dominant position by validating it with the help of a public social addressee based on his/her intertextual cultural competence. The essence of a stratagemically structured discourse consists of re-designing, that is, reframing the original scenario of the development of the situation into a different type of scenario. The stratagem is constructed on the basis of both precedent stratagems and non-precedent stratagems. A specific method of reframing can be put in accordance with the implicit prescriptive content of the literal formula of a phraseological unit as a sign of a certain type of stratagem in the Chinese language. Reframing the initial situations that determine the stratagem of the discourse allows us to implement various communicative strategies, the main of which are manipulative, imperative and developmental.
\end{abstract}

\section{Introduction}

The media political discourse generated by the situation of the struggle of interests and competitive positions in an axiologically parameterized space open to multiple addressees determines its basic agonal nature and intentionality for dominance, which projects a strategy to achieve a communicative victory [1], [2] with the ultimate goal of convincing the target addressee to accept the discursive positioning formed in this way. In this regard, the methods of strategic implementation of discourse in an agonal type of situation are of particular relevance, based, on the one hand, on a creative, unusual way of argumentation of one's position, on the other hand - on the activation of the addressee's discursive thinking for the purpose of introducing him/her to the promoted point of view. In this regard, stratagemism is understood as the nature of the pragmatic strategic organization of discourse, based on the structuring of the stratagem.

The task of this article is to determine the way to achieve a communicative victory in a discourse that has an explicit or implicit stratagem. The hypothesis of the study is that structuring a discourse of a stratagemic nature constructs the transformation of the scenario of seeing a referential situation in favor of the discursive positioning of the speaker. The methodological basis of the research is cognitive modeling based on frame analysis of discourse and content analysis. Following J. Lakoff, a frame is understood as an idealized cognitive model of data processing, representing a prototypically typed scheme of the structure of reflection and understanding of a referential situation [3].

\section{The main part}

The concept of "stratagem" in the Western European tradition goes back to the ancient Greek strategema, which means military affairs in general and military cunning in particular [4]. The general definition of this concept can be presented in the following form: "A stratagem is a military operation or technique, usually a trick designed to mislead or surprise the enemy in order to achieve an advantage" [5].

In Chinese culture, the concept of a stratagem (智谋

; 谋略 ; 策略) has existed for at least three millennia, it is attributed to the military treatises "Sun-tzu" and "Wu-tzu", attributed to famous ancient generals Sun Bin and $\mathrm{Wu} \mathrm{Qi}$, who lived in the era of the Fighting Kingdoms (V-III centuries BC). A stratagem is defined as a strategic plan in which some trap or trick is concluded for the enemy. Currently, 36 ancient Chinese military tricks are widely known (三十六计) [6], which are a special type of phraseological units of the Chinese language-chengyu (成语), consisting of four, less often three hieroglyphs containing thousands of years of experience of Chinese civilization [7]. The data of 36 stratagems, as noted by V. V. Malyavin, can be considered a precedent phenomenon of Chinese linguoculture, which has a supra-individual, collective character, while performing identifying, orienting (value-target) and modeling (attitude, way of perception, categorization and conceptualization) functions in communication, thereby introducing the addressee to the expressed meaning. In the study of Chinese stratagems,

\footnotetext{
Corresponding author: vgutsu@mail.ru
} 
attempts were made to classify their species. Thus, V. V. Malyavin in his work offers the following classification:

* Stratagems of victorious battles (借刀杀人 "using someone else's knife, kill a person").

* Stratagems at the balance of forces (无中生有 "to create something out of nothing").

* Stratagems of offensive battles (抛砖引玉 "throw a brick to get jasper").

* Stratagems of battles with several participants (远 交近攻 "make friends with distant and fight with neighbors").

* Stratagems of the battle together with a third party ( 上屋抽梯 "get on the roof and remove the ladder").

* Stratagems of losing battles (走为上 "escape is the best technique") [7].

A different classification is proposed by Harro von Sanger in his work "36 stratagems for managers":

* Masking stratagems (瞒天过海 "deceiving the emperor, crossing the sea").

* Stratagems-hoaxes (无中生有 "to create something out of nothing").

* Stratagems-exposures (打草惊蛇 "hitting the grass to scare the snake").

* Profit-making stratagems (趁火打劫 "rob during a fire").

* Coupling of stratagems (连环计 "stratagem" of the chain of tricks"").

* Escape stratagems (金蟾脱壳 "the cicada sheds its golden skin") [8].

In this paper, the stratagem is understood as a way to implement the strategy of discourse in a conflict situation, based on an attempt to reformat, reframe the scenario, some conflict situation in their favor, and, thereby, achieve a "communicative victory" in communication.

The expansion of the stratagem concept use to various spheres of activity, including the field of linguistics in terms of the study of effective linguistic influence ways, is based on a fairly rich experience in communication management, is rooted in the ways of displaying cultural and civilizational identity and is in demand when solving strategic, significant-scale tasks within the framework of "macro-communications", which is especially important for the mass media communicative space and the implementation of political communications. The phenomenon of stratagemicity in language has already been considered at the level of the analysis of paroemias in a comparative aspect [9]. At the same time, it was not the subject of special study in the analysis of discourse.

The appeal to the stratagem in the implementation of media political discourse is especially relevant in relation to Chinese political discourse. Along with its characteristics such as temporality, institutionality, publicity, evaluativeness, unidirectionality, stereotyping, mythologization [10], Chinese political discourse is characterized by the manifestation of its inclusion in cultural traditions, reliance on the value meanings of culture, intra-cultural intertextuality [11]. One of such linguistic and cultural supports is the stratagem. In this regard, the stratagem can be implemented as an explicit use/reproduction of a precedent phenomenon in discourse, contributing to the explicit construction of the vision of the situation in terms of confrontation, struggle, open conflict; or in the form of some standard, a model for this kind of construction, which is implicitly restored according to the circumstances of the communicative situation. From this point of view, the stratagem acts as a stereotypical image-associative complex, significant for a certain society [12].

In this regard, the study of Chinese political discourse as a form of political communication from the point of view of its stratagem makes it necessary to take into account the factor of explicit and non-explicit manifestations of this phenomenon in media texts that define this discourse.

The object of the analysis is Chinese political texts of the subject area of corruption, selected from Chinese Internet domains (www.chinanews.com, www.xinhuanet.com, www.cpc.people.com). The sample was carried out on the basis of a chronological cross-section in the period from 2013 to 2021. The corpus of texts comprised more than 20 media texts containing stratagems. The choice of the subject area of corruption is associated with its obvious agonality and the implication of the active, influencing nature of positioning in relation to the object of discursivization.

\section{Results of the study}

The first stage of the analysis was the identification of discursive stratagems of actual precedent knowledge in the Chinese political discourse and their content analysis in relation to discursive stratagems not of a precedent plan, but of precedent stratagems structured according to the functional potential. The following results were obtained during the analysis (Table 1):

Table 1. Results were obtained during the analysis

\begin{tabular}{|c|c|c|}
\hline & $\begin{array}{l}\text { Case-based } \\
\text { stratagems }\end{array}$ & $\begin{array}{l}\text { Non-Case-based } \\
\text { stratagems }\end{array}$ \\
\hline $\begin{array}{l}\text { Number of } \\
\text { stratagems }\end{array}$ & $3(14 \%)$ & $18(86 \%)$ \\
\hline $\begin{array}{l}\text { Semantic } \\
\text { pragmatic } \\
\text { load of } \\
\text { stratagems }\end{array}$ & $\begin{array}{l}2 \text { the stratagems } \\
\text { contain instructions for } \\
\text { the actions of the state } \\
\text { in the fight against } \\
\text { corruption } \\
\text { 釜底抽薪 fǔ dǐ chōu } \\
\text { xin - to get the } \\
\text { firewood from under } \\
\text { the pot (to apply } \\
\text { radical measures) } \\
1 \text { stratagem describes } \\
\text { the behavior of corrupt } \\
\text { officials 无中生有 wú } \\
\text { zhōng sheng yóu- } \\
\text { from nothing to create } \\
\text { something (achieving } \\
\text { results through }\end{array}$ & $\begin{array}{l}\text { 11 stratagems contain } \\
\text { instructions for the } \\
\text { actions of the state in the } \\
\text { fight against corruption } \\
\text { 除恶务尽 chú è wù jìn - } \\
\text { to destroy evil without a } \\
\text { trace (to wage an } \\
\text { uncompromising } \\
\text { struggle) } \\
3 \text { stratagems describe } \\
\text { the behavior of corrupt } \\
\text { officials } \\
\text { 移花接木 yí hua ji jie mù } \\
\text { - graft a flower to a tree } \\
\text { (substitution, fake) } \\
4 \text { stratagems express the } \\
\text { attitude of the state to }\end{array}$ \\
\hline
\end{tabular}




\begin{tabular}{|l|l|l|}
\hline & $\begin{array}{l}\text { minimum cost of } \\
\text { resources) }\end{array}$ & $\begin{array}{l}\text { corruption } \\
\text { 腐败是社会毒瘤 Fǔbài } \\
\text { shì shèhuì dúliu }- \\
\text { corruption is a tumor on } \\
\text { the body of society }\end{array}$ \\
\hline
\end{tabular}

The table shows that both groups of stratagems have similar semantic groups, but there is a significant prevalence of non-precedent stratagems (86\%) in relation to precedent ones $(14 \%)$. This phenomenon can be explained by the fact that new stratagems based on already existing prototypical stratagems are increasingly appearing in the modern Chinese media discourse (the 36 stratagems already mentioned earlier). At the same time, the main context of the communicative situation is the fight against corruption, and the state acts as the addressee.

The second stage of the analysis was the definition of the essence of conflict situations in which the discourse is implemented, and its representation in the form of a frame. Let us clarify that the frame in the work is understood as a cognitive typing model of data processing. The frame allows you to model not only the composition and relationships between the actors of the situation, but also the initial vision of the scenario of the situation.

As a result of the analysis, a frame of the initial conflict situation of the political discourse of the subject area corruption was constructed, which can be presented in the following form (Fig. 1):
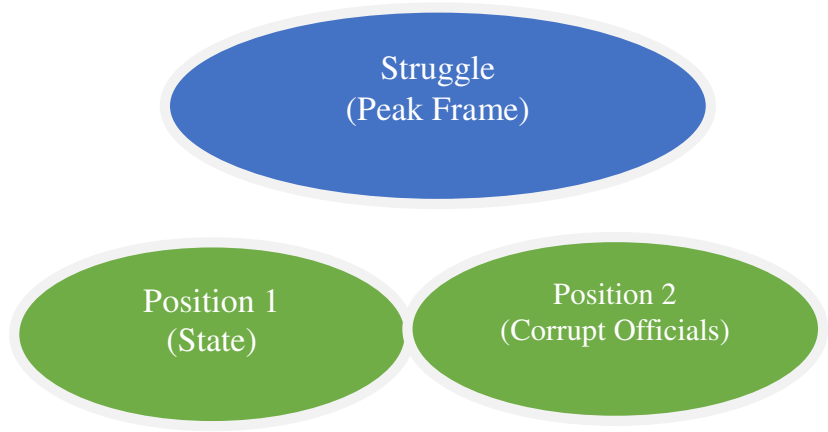

Figure 1. Frame of the initial conflict situation of the political discourse of the subject area corruption

As we can see, the top of the frame is the struggle, position 1 is the state, and position 2 is corrupt officials: enemies of the state, namely criminals and leaders of criminal groups. The initial vision of the anti-corruption scenario is presented in this form due to the fact that the state, namely its representatives - political leaders, without exception, are all institutionally, prototypically called upon to fight corruption.

Next, we will clearly use examples to consider how the source scripts are reframed, depending on the stratagems used by the addressees.

\section{（1） 《... 这也是中央打虎手段的创新：调虎离山 。这有助于更好地对官员进行调查, 有助于 拿下大老虎, 而不是让老虎们归隐山林...»}

\section{(http://finance.cnr.cn/gundong/20150303/t2015} $\underline{0303 \quad 517864888 . \mathrm{shtml})}$

'... in the fight against corruption, authorities have resorted to the innovative reception of "hunting tigers of the central committee": distraction (literally. to lure the tiger from the mountain to the plain). This "innovative" technique contributes to a more thorough investigation of officials, and to the arrest of the leaders of a criminal group ' (own translation from Chinese language).

The reframing of the initial situation looks like this (Fig. 2).

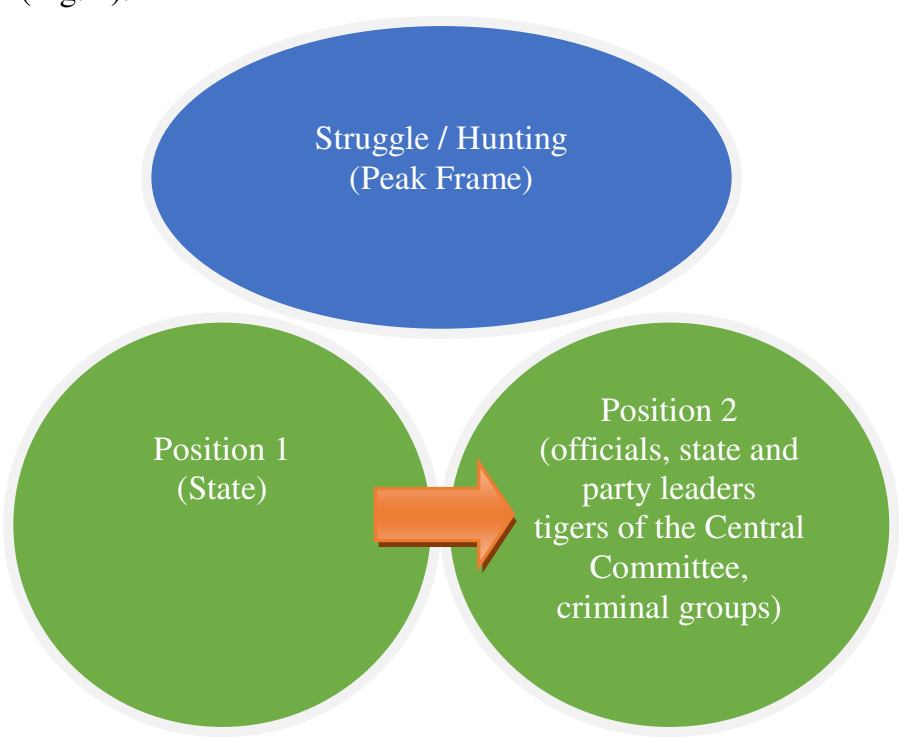

Figure 2. Reframing of the initial situation

In this text, the stratagem characterizes the actions of the state as "innovative", regulating the problem in an unexpected way ("lure"), in line with a manipulative strategy towards those persons who consider themselves untouchable, protected by the status of high bosses in the state and the party ("tigers"). In the process of communication, position 1 of the original frame is reversed due to the fact that statesmen act as the enemy (the criminal world, corrupt officials), while the top concept of "struggle" is replaced by the concept of "hunting", which assumes a different way of dealing with a dangerous and dexterous opponent in the image of a large predator, rather than an open confrontation with him. Thus, the stratagem changes the initial scenario of the vision of the situation of open struggle and validates, through a precedent stratagem, the vision of victory over corruption in the fight against itself and in the hunting scenario: luring, tricks, organizing hidden investigations, etc. This type of stratagem should be classified as a "masking exposure" stratagem. According to another classification, it is possible to characterize the stratagem of this political discourse in terms of "making friends with distant and fighting with neighbors".

\section{（2）《...四是深刻把握反腐败斗争新态势，一体} 推进不敢腐、不能腐、不想腐 ...» 
(http://politics.people.com.cn/n1/2021/0122/c10 24-32009284.html)

'... to take control of the situation of the struggle against corruption and to facilitate the implementation of the strategy "does not dare, can not, will not engage in corruption" ...' (own translation from Chinese language).

The reframing of the initial situation looks like this (Fig. 3):

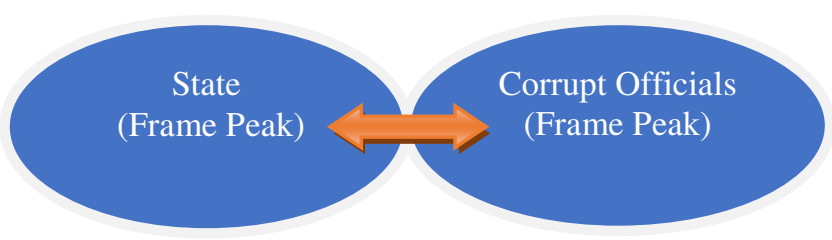

Figure 3. Reframing of the initial situation

In this example, the stratagem is used as a way to implement a developing strategy. The original frame (struggle) is restructured in such a way that "the sides themselves" become the top of the frame, while the very concept of "struggle", "opposing sides" disappears. The stratagem of the discourse reflects the essence of the precedent stratagem of "fighting together with a third party" with a prototypical representation in the formula "bring to the roof and remove the ladder". That is, in this case, they put citizens in the position of having no alternative and independent choice of action on the right side in a situation of open struggle against the "second party" - corrupt criminals.

(3) 《... 要正视严峻的形势, 严肃纪律, 严惩腐 败, 坚决落实党风廉政建设党委的主体责任 和纪委的监督责任。有问题并不可怕, 怕的 是对问题麻木不仁, 要对症下药.... (http://jhsjk.people.cn/article/26366130).

' ... it is necessary to openly look at the difficult situation, observe discipline, punish corruption, firmly follow the plan for the implementation of the creation of an uncorrupted government and party. If problems arise, you can not show indifference, you need to take targeted measures (before prescribing medicine in accordance with the disease) ...' (own translation from Chinese language).

The reframing of the initial situation looks like this (Fig. 4).

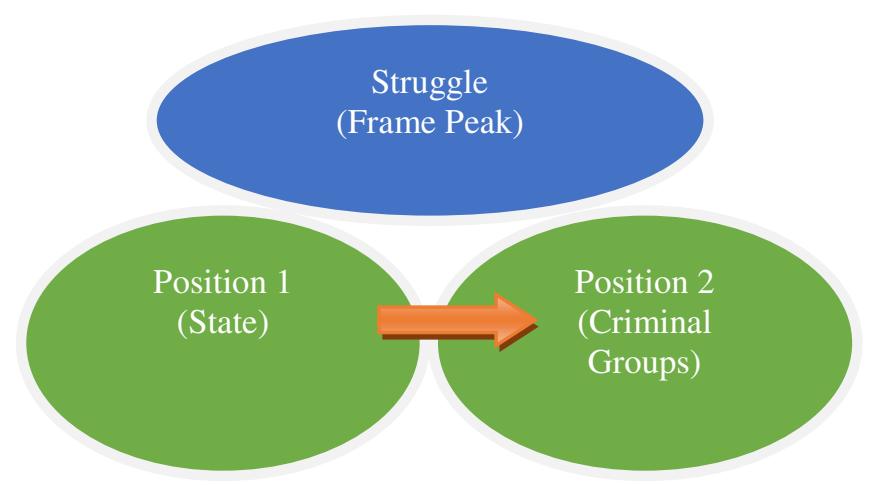

Figure 4. Reframing of the initial situation

In this example, the stratagem is used as a way to implement a developmental strategy that is based on a dialogue of communicants and their mutual openness, consent according to the model of a patient who is aware of his illness and takes medicine as a necessary measure for recovery. The struggle at the top of the original prototic frame is replaced by the concept of fighting the disease, and not with its carrier. The precedent-based stratagem thus contributes to a change in the vision of the anti-corruption scenario. Interaction occurs between the actors of the situation in the communicative roles of the doctor and the patient, and develops not by suppressing corruption and punishing corrupt officials, but by "medical means" of diagnosis and treatment, the purpose of which is the recovery of the patient. We can conclude that in this case, the stratagem of the discourse is realized by the type of "stratagems at the balance of forces" in the representative formula (无中生有 "to create something out of nothing").

\section{（4） 《 ... 深入推进反腐败斗争... 凡腐必反，除恶 务尽..." \\ (http://jhsjk.people.cn/article/26366130).}

' ...to strengthen the struggle against corruption... as a result, corruption will be destroyed (literally, destroy evil without a trace)' (own translation from Chinese language).

The frame of this situation corresponds to the frame of the original situation and looks like this (Fig. 5).

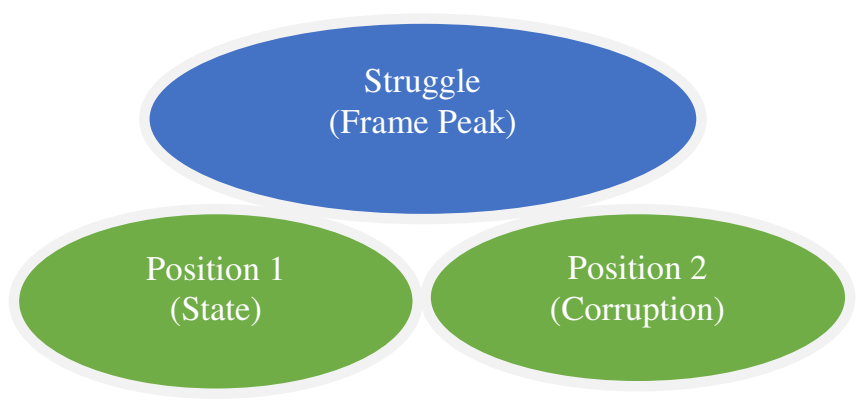

Figure 4. Reframing of the initial situation

In this case, the stratagem is used as an imperative strategy technique. The addressee openly expresses his intentions, namely, to overcome corruption, thereby winning a "victory". In this case, the stratagem of the discourse is realized by the type of "stratagem of offensive battles" according to the formula (抛砖引玉 "throw a brick to get jasper").

\section{Conclusions}

Thus, the stratagemic nature of the Chinese media discourse reflects a number of its linguistic and cultural features, manifests itself in the coordinates of the 
political macro-communication, which has an agonal character and is focused on achieving a dominant position by validating it with the help of a public social addressee based on background knowledge and intertextual cultural competence. The stratagem is constructed on the basis of both precedent stratagems and non-precedent stratagems structured according to the precedent matrix. The dominance and achievement of a communicative victory in a stratagemically structured discourse is achieved by redesigning, that is, reframing the original prototypical scenario of the development of the situation into a different kind of scenario. The method of reframing can be put in accordance with the implicit prescriptive content of the literal formula of a phraseological unit as a sign of a certain type of stratagem in the Chinese language. Reframing the initial situations that determine the stratagem of the discourse allows us to implement various communicative strategies, the main of which are manipulative, imperative and developmental.

\section{References}

1. Ya. Khintikka. Logical and Epistemological Studies. A collection of selected articles. P. 257 (Moscow: Progress, 1980).

2. J. Huizinga. A Person Who Plays. The Experience of Determining the Game Element of Culture. Page 86 (St. Petersburg: Ivan Limbach Publishing House, 2011).

3. J. Lakoff. Women, Fire and Dangerous Things: What the Categories of Language Tell Us About Thinking. pp. 99-107 (Moscow: Languages of Slavic Culture, 2004).

4. H. von Sanger. Stratagems. About the Chinese Art of Living and Surviving. Vol. 2. Page 19 (Moscow: Eksmo, 2006).

5. N. M. Katkova. The Stratagem of Thinking and Behavior as a Characteristic Feature of Chinese Civilization. Bulletin of the Saint Petersburg University. Series 13: Oriental Studies. African studies. No. 2. p. 78 (2011).

6. 马 马, 全晰纲. 三十六计. 文文书局, 武汉 (2014).

7. V. V. Malyavin. Thirty-six Stratagems. Chinese Secrets of Success. Page 6 (Moscow: Belye Alva, 2000).

8. H. von Sanger. 36 Stratagems for Managers (Moscow: Olymp-Business Publishing House, 2017).

9. S. V. Sidorkov. Functional and Semantic Aspects of Language Stratagem // Diss. ... Candidate of Philology (Krasnodar, 1997).

10. O. I. Kalinin. Linguopragmatic Characteristics of the Image Political Media Text (Based on the Material of the Chinese Media). Diss. ... Candidate of Philology. n. Page 35 (Moscow, 2017).

11. T. E. Litvinenko. Intertext in Aspects of Linguistics and General Text Theory: Monograph (Irkutsk: IGLU Publishing House, 2008).

12. V. N. Telia. Russian Phraseology. Semantic, Pragmatic and Linguoculturological Aspects (Moscow: School "Languages of Russian Culture", 1996). 